\title{
Floresta Júnior: Projeto de apoio à formação e a capacitação acadêmica
}

\author{
Débora da Silva Teixeira ${ }^{1}$, Jorge Antonio de Farias ${ }^{2}$
}

\begin{abstract}
Resumo: O termo "Empresa Júnior", surgiu em 1967, na França, e tratava-se de um projeto do governo para incentivar a criação de empresas no país. Hoje, o papel das empresas juniores é dar aos acadêmicos a oportunidade de aprimoramento técnico através da realização de trabalhos que possibilitem a resolução de tarefas práticas, desenvolvimento pessoal e valorização da profissão, além de contribuir com o desenvolvimento da sociedade, através dos trabalhos de extensão realizados em sua área de atuação, tendo como resultado final a interação Universidadel Comunidade. Este trabalho descreve a Floresta Jr, empresa júnior criada como forma de cooperar para a formação técnica e humana da comunidade em geral e dos acadêmicos de Engenharia Florestal da Universidade Federal de Santa Maria, a Floresta Jr. propõe a realização de trabalhos técnicos, palestras e cursos. Conclui-se que a Floresta Jr. facilita a inserção dos acadêmicos no mercado de trabalho, com a criação de um canal de divulgação da profissão e de contato dos estudantes com empresas e profissionais do ramo.
\end{abstract}

Palavras-chave: Empresa Júnior. Extensão. Formação acadêmica. Aprimoramento técnico. Engenharia Florestal.

Área Temática: Educação.

\section{Floresta Júnior: Project to support academic education and training}

\begin{abstract}
The term "Junior Company ", appeared in 1967, in France, was a government project to encourage the creation of companies in the country. Today, the role of junior companies is to give academics the opportunity for technical improvement through carrying out works that enable the resolution of practical tasks, personal development and appreciation of the profession, in addition to contributing to the development of society, through extension work carried out in its area of activity, with the final result of the University / Community interaction. This work describes Floresta Jr., a junior company created as a way to cooperate for the technical and human formation of the community in general and of the students of Forest Engineering at the Federal University of Santa Maria, Floresta Jr. proposes technical works, lectures and It is concluded that Floresta Jr. facilitates the insertion of academics in the job market, with the creation of a channel to publicize the profession and contact of students with companies and industry professionals.
\end{abstract}

Keywords: : Junior Company. Extension. Education. Technical improvement. Forestry.

\section{Floresta Júnior: Proyecto de apoyo al entrenamiento y formación académica}

Resumen: El término "Empresa Junior", apareció en 1967, en Francia, y fue un proyecto del gobierno para incentivar la creación de empresas en el país. Hoy en día, el papel de las empresas junior es brindar a los académicos la oportunidad de mejora técnica a través de realizar trabajos que permitan la resolución de tareas prácticas, el desarrollo personal y la valoración de la profesión, además de contribuir al desarrollo de la sociedad, a través de la labor de extensión que se realice en su área de actividad, con el resultado final de la interacción Universidad /

\footnotetext{
${ }^{1}$ Engenheira Florestal, MSc., Doutoranda do Programa de Pós-graduação em Engenharia Florestal, Centro de Ciências Rurais, Universidade Federal de Santa Maria, Av. Roraima, 1000, CEP 97105-900, Santa Maria (RS), Brasil. dehbora_teixeira@hotmail.com

2 Engenheiro Florestal, Dr., Professor do Departamento de Ciências Florestais, Centro de Ciências Rurais, Universidade Federal de Santa Maria, Av. Roraima, 1000, CEP 97105-900, Santa Maria (RS), Brasil. fariasufsm@gmail.com
} 
Comunidad. Este trabajo describe Floresta Jr., una empresa junior creada como una forma de cooperar para la formación técnica y humana de la comunidad en general y de los estudiantes de Ingeniería Forestal de la Universidad Federal de Santa María, Floresta Jr. propone trabajos técnicos, charlas y Se concluye que Floresta Jr. facilita la inserción de académicos en el mercado laboral, con la creación de un canal para dar a conocer la profesión, y contacto de estudiantes con empresas y profesionales de la industria.

Palabras clave: Empresa junior. Extensión. Formación académica. Mejora técnica. Ingeniería Florestal.

\section{INTRODUÇÃO}

O termo “Empresa Júnior”, surgiu em 1967, na França, e tratava-se de um projeto do governo com o objetivo de incrementar a criação de novas empresas e obter, assim, a renovação da economia daquele país (UNIVERSIDADE FEDERAL DO PARANÁ, 2020). Com a ideia pioneira de se montar uma associação de alunos que os aproximassem do mercado de trabalho, através de serviços oferecidos pelos mesmos, universitários de uma Escola de Paris criaram, em 1967, a primeira Empresa Júnior, na qual colocariam todos os seus conhecimentos teóricos em prática (UNIVERSIDADE FEDERAL DO PARANÁ, 2020). Hoje, na Europa, é uma experiência bem sucedida, onde só na França, mobiliza em torno de oito mil universitários, nas cerca de 180 empresas juniores espalhadas pelo país, nas mais variadas áreas de atuação, movimentando o faturamento de aproximadamente US\$20 milhões/ano (MATOS,1996).

Mesmo obtendo enorme sucesso na Europa, a primeira Empresa Júnior brasileira foi criada apenas em 1988, pelos estudantes da Fundação Getúlio Vargas. Já em 1994, foi fundada a primeira EJ da Universidade Federal de Santa Maria, a Objetiva Júnior (OBJETIVAJR., 2020). Hoje existem no Brasil cerca de 600 empresas juniores, mapeadas em mais de 200 Instituições de Ensino Superior em todos os Estados Brasileiros e Distrito Federal, contando com o envolvimento de mais de 23 mil universitários. Elas são representadas por federações estaduais, que juntas formam a Confederação Brasileira de Empresas Juniores. Em torno de 60\% destas Empresas Juniores são provenientes de IES públicas (MEJ, 2020).

O movimento, dirigido por estudantes universitários preocupados com uma experiência profissional, o MEJ (Movimento das Empresas Juniores) segue uma ideologia isenta de fins econômicos assim como de parcerias com correntes políticas (MEJ, 2020). Com todo suporte intelectual e de infraestrutura que as faculdades dispõem a Empresa Júnior procura prestar serviços a baixo custo, sendo bem vista por seus clientes, satisfeitos em obter tamanha qualidade. São estimados 2000 projetos de consultoria, principalmente para Micro e Pequenas Empresas, desenvolvidos a cada ano pelas Empresas Juniores (PICCHIAI, 2008).

A gerência das Empresas Juniores é feita pelos estudantes, porém a orientação profissional em todos os projetos é função dos professores, já que possuem subsídios intelectuais para isso. Os professores também consistem em uma importante ferramenta de ligação com os setores mais elevados da Universidade. Cabe destacar que o Movimento das Empresas Juniores (MEJ) contribui com uma importante parcela no desenvolvimento empresarial e econômico do país (MEJ, 2020). 
Atualmente o papel das empresas juniores é dar aos acadêmicos a oportunidade de aprimoramento técnico, através da realização de trabalhos, que possibilitem a resolução de tarefas práticas, desenvolvimento pessoal, complemento à formação teórica (fornecendo experiência), valorização da profissão, do Curso, da Instituição (universidade), dos mestres e, sobretudo, do acadêmico engajado em tal projeto, além de contribuir ao desenvolvimento da sociedade através de um trabalho de extensão a ser realizado em sua área de atuação, tendo como resultado final a interação Universidade/Comunidade (LASMAR et al, 2016),

Este trabalho descreve a Floresta Jr., empresa júnior criada como forma de cooperar para a formação técnica e humana da comunidade em geral e dos acadêmicos de Engenharia Florestal da Universidade Federal de Santa Maria, propondo a realização de trabalhos técnicos, palestras e cursos de curta duração e trabalhos sociais voltados a áreas em que apresentam carências.

\section{OBJETIVOS}

Este relato tem como objetivo descrever as atividades realizadas pela Floresta Jr, empresa Júnior do Curso de Engenharia Florestal da Universidade Federal de Santa Maria, bem como sua importância na formação dos acadêmicos e benefícios à sociedade.

\section{METODOLOGIA}

Este artigo trata-se de um trabalho exploratório e descritivo, cuja principal fonte de dados são os arquivos e publicações da própria empresa Floresta Jr., vinculada ao curso de graduação em Engenharia Florestal da Universidade Federal de Santa Maria, que permitiu gentilmente o acesso aos seus bancos de dados, sendo então realizado um relato descritivo das atividades realizadas pela empresa no período entre os anos $2012 \mathrm{e}$ 2016, além de uma análise qualitativa da atuação profissional dos integrantes da empresa.

\section{RESULTADOS E DISCUSSÃO}

Fundada por alunos do curso de Engenharia Florestal da UFSM, em 12 de maio de 1998 a Floresta Jr. surgiu como um meio de mostrar aos estudantes como uma empresa funciona, além de proporcionar aos acadêmicos do curso de Engenharia Florestal uma maior interação entre a teoria obtida nas salas de aulas e a prática a campo. Nesta época o curso apresentava um alto índice de evasão e desistência, fato este que motivou a criação da empresa. Isto acontecia, pois os alunos não conheciam a real estrutura, os objetivos do Curso, ou pior, confundiam com o "modismo ambiental", menosprezando a funcionalidade da engenharia. Após a realização de um estudo sobre o número de ingressos e egressos, questionando acadêmicos e professores, identificou-se o real problema: o excesso de conteúdo teórico ministrado durante as aulas, associado a poucas aulas práticas. 
A Floresta Jr. tem sua sede no Centro de Ciências Rurais da UFSM, no subsolo do prédio 44, sala 5012. Conta com o apoio técnico de Engenheiros, Professores e dos Departamentos que englobam os campos da Ciência Florestal. AFloresta Jr. tem como missão antecipar a realidade profissional aos estudantes de graduação através do desenvolvimento de projetos e relacionamento com a sociedade, mantendo os princípios da UFSM, de educação, extensão e pesquisa.

Frente à preocupação geral da sociedade com as condições do meio ambiente, a Floresta Jr. procura contribuir para a conservação dos recursos naturais, aliando novas tecnologias, dinâmica e criatividade às suas ações; e acredita que a preparação profissional engloba a formação acadêmica, participação em eventos, cursos extracurriculares, participação em trabalhos práticos, contato com profissionais e com o mercado de trabalho. Para ser um bom profissional não basta ter especialização, é necessário versatilidade, polivalência, ser capaz de atuar em diferentes campos de trabalho, ser líder, dinâmico e criativo, e é esta a contribuição da Floresta Jr. à comunidade acadêmica.

Ocupam o quadro de membros da empresa, em média, 12 acadêmicos de graduação. O processo de participação dos alunos na Floresta Jr. é dinâmico, pois a cada semestre novos acadêmicos são selecionados para fazer parte do grupo, ocupando as vagas daqueles que saem por concluírem a graduação. Durante o período estudado a empresa abriu, em média, quatro novas vagas a cada semestre, ocupadas por alunos selecionados em processos seletivos de várias etapas, contando com entrevista individual e coletiva, dinâmicas de grupo e resolução de problemas práticos constantes nas rotinas da vida profissional.

A Empresa Floresta Jr. atende principalmente o mercado dos pequenos e médios produtores rurais que não tem acesso à consultoria sênior de empresas e enfrentam dificuldades na gestão de suas propriedades.

A fim de garantir um ótimo aprendizado acadêmico, todo o trabalho executado é auxiliado por um docente, específico da respectiva área de conhecimento, sem vínculo à Empresa Floresta Jr., visto que esses trabalhos são prestados como consultoria a todo tipo de média e pequena empresa, embora o mercado alvo seja o PPMR (pequeno e médio produtor rural). O coordenador geral (docente), é responsável por gerenciar os serviços, minicursos e eventos efetuados pela empresa. Para cada área de atuação referente à graduação de Engenharia Florestal, a empresa estipulou um coorientador que auxilia diretamente em cada projeto.

A empresa realiza diversas atividades, as quais evidenciam sua importância para a qualificação dos futuros profissionais tornando-os aptos a exercerem a profissão legal de Engenheiro Florestal. Estes trabalhos envolvem os membros da empresa e demais acadêmicos que venham participar como voluntários das atividades desenvolvidas pela Empresa Floresta Jr.

São realizados junto a Universidade Federal de Santa Maria - UFSM, eventos, tais como: minicursos e fóruns referentes à produção florestal, demanda e oferta de mercado referentes a questões ambientais, direcionados à comunidade acadêmica, munícipes, produtores rurais e demais interessados. Além disso, a empresa presta 
serviços técnicos com o intuito de desenvolver os aspectos teóricos absorvido em sala de aula e aplicá-los de forma prática em campo, aprimorando as técnicas dos produtores rurais. Dentre eles:

- Inventário florestal: reservas florestais, áreas de manutenção da vida silvestre, áreas de reflorestamento comercial; - Levantamento fitossociológico: quantificação da composição florística, estrutura, funcionamento, dinâmica e distribuição de uma determinada vegetação;

- Projetos de arborização urbana e paisagismo: áreas verdes, praças, parques;

- Projetos de educação ambiental: educação ambiental técnica voltados à comunidade;

- Silvicultura: tratos e métodos silviculturais, sistemas agropastoris e agroflorestais.

Os serviços oferecidos têm o foco principal de auxiliar na supressão das principais dificuldades encontradas pelo produtor rural nas técnicas de implantação florestal.

Os membros da Empresa Floresta Jr., têm um diferencial frente ao mercado de trabalho competitivo, participam da administração da empresa e saberão atuar na prática, após terem concluído a graduação, conforme as necessidades do seu setor de trabalho. Vivenciam a organização do trabalho em equipe, delegação de responsabilidades, disciplina, negociações, atividades financeiras, tomada de decisões, convívio com riscos e o contato direto com a realidade do público atendido.

Dentre as principais atividades desenvolvidas pela Floresta Jr., durante o período levantado neste trabalho, pode-se citar:

1) Projeto de arborização urbana e paisagismo no município de Saldanha Marinho - RS: O projeto foi realizado no ano de 2012, contou com a participação direta de seis membros da Floresta Jr, sendo os outros seis membros prestadores de suporte. Foram beneficiados os 3.000 moradores da cidade;

2) Curso de Licenciamento Ambiental: O Curso, que teve como público alvo os alunos de graduação e pósgraduação de Engenharia Florestal da UFSM, contou com aulas teóricas e práticas ministradas para 46 acadêmicos;

3) Levantamento mercadológico dos preços e sortimentos de madeira na cidade de Santa Maria e arredores: O levantamento, realizado no ano de 2016, foi realizado pelos 12 membros da Floresta Jr., e contou com a pesquisa de mais de 50 pequenas e médias indústrias de processamento e venda de madeira da região;

4) InterFloresta: Evento realizado nos anos de 2013 (80 participantes), 2014 (140 participantes) e 2015 (90 participantes), onde foram ministradas palestras, minicursos e jogos, para acadêmicos da UFSM e outras instituições de ensino superior;

5) "Canto do pica-pau": Evento cultural realizado anualmente, destinado à integração dos alunos através da música, conta com a participação de aproximadamente 40 pessoas a cada edição;

6) Cursos de Excel: Os cursos de Excel são ministrados de anualmente, e têm como público alvo os acadêmicos de graduação em Engenharia Florestal da UFSM. A cada edição são disponibilizadas duas turmas, cada uma com 20 vagas; 
7) Feira das profissões (PROFITECS e Descubra UFSM): O evento, realizado no Campus Sede da UFSM, tem por objetivo central divulgar aos visitantes os cursos e iniciativas de ensino, pesquisa e extensão da Universidade. Realizado anualmente desde 1998, conta com um público de, aproximadamente, 25 mil pessoas a cada edição. No evento, a Floresta Jr., em parceria com a Coordenação do Curso de Engenharia Florestal, é responsável pela montagem e atendimento no estande destinado à divulgação do curso.

Além da própria integração entre os membros e demais componentes da comunidade acadêmica, o relacionamento entre os alunos participantes e o mercado, ativa o espírito empreendedor, aumenta o contato com a atuação em possíveis áreas de interesse, agregando uma maior carga de conhecimento. A concretização dos projetos também traz consciência da responsabilidade social, pois beneficiam a sociedade em geral, sendo o conhecimento passado da academia diretamente para a aplicação em empresas, propriedades rurais e a outros interessados, com preços acessíveis que geram uma melhor distribuição destas novas tecnologias a todos, mesmo os que dispõem de menos recursos.

\section{CONCLUSÕES}

Por meio dos resultados obtidos, foi possível identificar as principais áreas de atuação da Floresta Jr. e sua importância na formação de profissionais mais dinâmicos e comprometidos com o bem estar da sociedade em que irão atuar.

Conclui-se que a Floresta Jr. facilita a inserção dos acadêmicos no mercado de trabalho, com a criação de um canal de divulgação da profissão e de contato dos estudantes com empresas e profissionais do ramo.

Além disso, propõe-se, como forma de facilitar a inserção dos estudantes e egressos da Engenharia Florestal da UFSM no mercado de trabalho, a criação de um canal de divulgação da profissão e a criação de possibilidades de contato dos estudantes com empresas do ramo, através de feiras e outros eventos. A Floresta Júnior também atua no mercado, prestando consultoria para pequenas e médias empresas, produtores rurais, indústrias, órgãos públicos, além disso, foca suas atividades no desenvolvimento dos acadêmicos e da sociedade.

\section{REFERÊNCIAS}

LASMAR, Tiago Paz; REIS, Marina Carelli; CARVALHO JUNIOR, Gerson Geraldo; DIAS, Ana Valéria Carneiro; PEREIRA, Maria Cecília. O papel das empresas juniores na formação dos estudantes de graduação em engenharia de produção: uma análise a partir da percepção de seus membros. $X X X V I$ Encontro Nacional de Engenharia de Produção, 2016. Disponível em: < http://www.abepro.org.br/ biblioteca/TN_STO_235_367_30853.pdf>.Acesso em:08 Dez. 2020.

MATOS, Leonardo M.C. A CEFET Júnior. Revista Educação \& Tecnologia. Edição Jul./Dez., 1996. Disponível em: < https://periodicos.cefetmg.br/index.php/revista-et/article/viewFile/187/187 >. Acesso em: 25 Mar. 2020. 
Movimento Empresa Júnior - Brasil Junior - MEJ. Conheça o MEJ. Disponível em: < http:// www.brasiljunior.org.br/brasiljunior >. Acesso em: 25 Mar. 2020.

OBJETIVAJUNIOR. Quem somos. Disponível em: < http://www.objetivajr.com.br/quem-somos >. Acesso em: 25 Mar. 2020.

PICCHIAI, Djair. Empresa Júnior, um exemplo de pequena empresa. Revista Administração em Diálogo, São Paulo, v. 2, n. 11, 2008, p. 35-52.

UNIVERSIDADE FEDERAL DO PARANÁ. Empresas Juniores da UFPR. Disponível em: <http:// www.ufpr.br/portalufpr/servic os/empresas-juniores/>. Acesso em: 25 Mar. 2020.

Submetido em: 15/08/2020 Aceito em: 21/01/2021. 